\title{
Study of community acquired pneumonia aetiology (SCAPA) in adults admitted to hospital: implications for management guidelines
}

\author{
W S Lim, J T Macfarlane, T C J Boswell, T G Harrison, D Rose, M Leinonen, P Saikku
}

Respiratory Infection Research Group,

Respiratory Medicine, Nottingham City

Hospital, Hucknall

Road, Nottingham

NG5 1PB, UK

W S Lim

J T Macfarlane

Department of

Medical Microbiology

T C J Boswell

Department of Diagnostic Radiology

D Rose

Respiratory and Systemic Infection Laboratory, Central Public Health

Laboratory, Colindale, London NW9 5EQ, UK

T G Harrison

National Public Health Institute, Department in Oulu, FIN-90101 Oulu, Finland

M Leinonen

Department of

Medical Microbiology, University of Oulu,

FIN-90401 Oulu,

Finland

P Saikku

Correspondence to: Dr J T Macfarlane john.macfarlane@ nottingham.ac.uk

Received 25 August 2000 Returned to authors 23 October 2000

Revised version received

24 November 2000

Accepted for publication

18 December 2000

\begin{abstract}
Background-Since the last British study of the microbial aetiology of community acquired pneumonia (CAP) about 20 years ago, new organisms have been identified (for example, Chlamydia pneumoniae), new antibiotics introduced, and fresh advances made in microbiological techniques. Pathogens implicated in CAP in adults admitted to hospital in the UK using modern and traditional microbiological investigations are described.

Methods-Adults aged 16 years and over admitted to a teaching hospital with CAP over a 12 month period from 4 October 1998 were prospectively studied. Samples of blood, sputum, and urine were collected for microbiological testing by standard culture techniques and new serological and urine antigen detection methods.
\end{abstract}

Results-Of 309 patients admitted with CAP, 267 fulfilled the study criteria; 135 $(50.6 \%)$ were men and the mean (SD) age was 65.4 (19.6) years. Aetiological agents were identified from $199(75 \%)$ patients (one pathogen in $124(46 \%)$, two in 53 $(20 \%)$, and three or more in $22(8 \%))$ : Streptococcus pneumoniae 129 (48\%), influenza A virus 50 (19\%), Chlamydia pneumoniae 35 (13\%), Haemophilus influenzae 20 (7\%), Mycoplasma pneumoniae 9 (3\%), Legionella pneumophilia 9 (3\%), other Chlamydia spp 7 (2\%), Moraxella catarrhalis 5 (2\%), Coxiella burnetii $2(0.7 \%)$, others 8 (3\%). Atypical pathogens were less common in patients aged 75 years and over than in younger patients $(16 \% v 27 \%$; OR $0.5,95 \%$ CI 0.3 to $0.9)$. The 30 day mortality was $14.9 \%$. Mortality risk could be stratified by the presence of four "core" adverse features. Three of 60 patients $(5 \%)$ infected with an atypical pathogen died.

Conclusion-S pneumoniae remains the most important pathogen to cover by initial antibiotic therapy in adults of all ages admitted to hospital with CAP. Atypical pathogens are more common in younger patients. They should also be covered in all patients with severe pneumonia and younger patients with non-severe infection.

(Thorax 2001;56:296-301)

Keywords: adult community acquired pneumonia; pathogens; aetiology; severity assessment
Community acquired pneumonia (CAP) is common in the UK, affecting 250000 adults per year of whom 83000 (33\%) are admitted to hospital ( $67 \%$ for patients aged 65 years and over). ${ }^{1}$ Mortality ranges from $6 \%$ to $15 \% .^{2-4}$

Initial antibiotic management of CAP is empirical and dependent on a clear understanding of the likely pathogens. In the UK this knowledge is based on studies performed in the 1970s and early 1980s. ${ }^{5}$ The largest study, conducted by the British Thoracic Society (BTS) in 1982, excluded adults over 74 years of age, thus missing the group of patients who carry the burden and mortality of CAP. ${ }^{3}$

In the last two decades a number of factors have potentially affected the pattern of adult CAP in the UK. The increasing age of the population, often with co-morbid illnesses or resident in residential and nursing homes, has raised concerns of Gram negative enteric bacterial infection in CAP. ${ }^{6}$ Concerns of antibiotic resistance and the emergence of "new" pathogens such as Chlamydia pneumoniae, implicated in $3-18 \%$ of cases of CAP elsewhere, ${ }^{7-9}$ has led to the promotion of fluoroquinolones and newer macrolides for the treatment of CAP. ${ }^{10}$

The impact of these changes on the microbial aetiology of CAP in the UK and how they should influence new management guidelines is unknown. We have performed a large prospective study of the aetiology of CAP and the outcome in adults admitted to hospital using a wide range of microbiological investigations.

\section{Methods}

All adults aged 16 years and over admitted to a large teaching hospital (Nottingham City Hospital) over a 12 month period from 4 October 1998 with CAP were eligible for inclusion in the study. The hospital shares all unselected adult medical admissions on a daily basis equally with the University Hospital in Nottingham, both covering a population of about 700000

All patients admitted with a provisional diagnosis of CAP were identified in the admissions unit where standardised clinical data and investigations were obtained. CAP was defined as the presence of an acute illness of 21 days or less duration with:

(1) features of a lower respiratory tract infection including:

(a) two or more of: new or increasing cough, sputum production, shortness of breath, wheeze, chest pain, new focal or diffuse signs on chest examination; 
Table 1 Criteria for microbiological diagnosis

\begin{tabular}{|c|c|}
\hline Organism & Diagnostic criteria \\
\hline All bacteria & $\begin{array}{l}\text { Isolation from blood processed in Bactec } 9240 \text { system or from pleural fluid, bronchoscopic aspirates, } \\
\text { or post mortem lung aspirates }\end{array}$ \\
\hline$S$ pneumoniae, $H$ influenzae or $M$ catarrhalis infection & $\begin{array}{l}\text { (a) Isolation from washed and diluted sputum in significant numbers by semiquantitative culture or } \\
\text { (b) for } S \text { pneumoniae: } \\
\text { - Pneumococcal antigen (PCA) detected in urine (BINAX-NOW kit, results read at } 60 \text { minutes) } \\
\text { or in sputum by countercurrent immunoelectrophoresis (CIE) or } \\
\text { (c) Serological criteria for } S \text { pneumoniae: } \\
\text { - } \geqslant 3 \text {-fold rise in antibody titre against C-polysaccharide (CPS) or } \geqslant 2 \text {-fold rise against } \\
\text { pneumolysin (PLY), pneumococcal surface antigen A (PsaA) }{ }^{22} \text { or PLY-, PsaA- or CPS-specific } \\
\text { immune complexes detected } \\
\text { (d) Serological criteria for } H \text { influenzae or } M \text { catarrhalis: } \\
\text { - } \geqslant 3 \text {-fold rise in antibody titre }{ }^{24}\end{array}$ \\
\hline $\begin{array}{l}\text { Infection with other bacteria including Gram negative } \\
\text { enterobacteria (GNEB) and Staph aureus }\end{array}$ & $\begin{array}{l}\text { The predominant organism in the sputum Gram stain in addition to isolation from washed and diluted } \\
\text { sputum in significant numbers by semiquantitative culture }\end{array}$ \\
\hline $\begin{array}{l}\text { Atypical and viral pathogens } \\
C \text { pneumoniae }\end{array}$ & $\begin{array}{l}\text { (a) at least 3-fold rise in IgG or IgA antibodies or } \\
\text { (b) presence of IgM antibody, using EIA kit (Labsystems, Helsinki, Finland) }\end{array}$ \\
\hline L pneumophila & $\begin{array}{l}\text { Isolation of organism from respiratory samples or Legionella antigen detected in urine by Biotest kit }{ }^{25} 26 \\
\text { or } 4 \text {-fold or greater rise in immunofluorescent antibody titre to } \geqslant 64 \text { using formalised yolk sac antigen } \\
\text { to L pneumophila serogroup } 1\end{array}$ \\
\hline $\begin{array}{l}\text { M pneumoniae, Chlamydia spp, C burnetti, influenza A and } \\
\mathrm{B} \text {, respiratory syncytial virus (RSV) and adenoviruses }\end{array}$ & 4 -fold or greater antibody rise or a single titre of $\geqslant 128$, by complement fixation test \\
\hline
\end{tabular}

Serum samples were tested at the National Public Health Institute, Department in Oulu, Finland for antibody responses to $C$ pneumoniae, $H$ influenzae, $M$ catarrhalis, and $S$ pneumoniae. Urine antigen testing was performed in conjunction with the Central Public Health Laboratory, Colindale, London, UK.

The criteria used to define infection in the 1982 BTS study were followed, updated for new investigations and pathogens. ${ }^{3}$

(b) one or more constitutional symptoms including fever, confusion, sweating, headaches, aches and pains, sore throat or coryza;

(2) radiographic shadowing on an admission chest radiograph consistent with infection and which was neither pre-existing nor of other known cause; and

(3) treatment with antibiotics for pneumonia by the attending physician.

Patients were excluded if the pneumonia was (a) not the primary cause for hospital admission, (b) an expected terminal event or (c) distal to bronchial obstruction (for example, from lung cancer). Patients with tuberculosis and HIV infection were excluded as were those who had been in hospital within the previous 10 days, were immunocompromised (received chemotherapeutic agents during 6 month period before admission or more than the equivalent of prednisolone $10 \mathrm{mg}$ daily for at least 3 months before admission), or had previously been entered in the study. Comorbid illness was defined as the presence of any of the following conditions for which the patient was under active medical supervision or was receiving treatment at the time of hospital admission: chronic lung disease, cardiac disease (ischaemic heart disease, cardiac failure, hypertension, atrial fibrillation), cerebrovascular disease (including previous transient ischaemic attacks), cognitive impairment, diabetes mellitus, chronic liver disease, chronic renal disease, and inflammatory rheumatological disorders (excluding osteoarthritis). Mental confusion was defined as an abbreviated mental test score of 8 or less and severe pneumonia was defined using the modified BTS (mBTS) severity rule. ${ }^{7}$ For the benefit of the discussion, patients aged 75 years and over are termed "elderly". The study was approved by the Nottingham City Hospital ethics committee.

Patients were seen within 24 hours of admission by a study investigator to confirm study entry criteria and informed consent. All chest radiographs were reviewed by an experienced radiologist (DR) blinded to patient details to confirm the radiographic study entry criteria. All patients were seen regularly in hospital and after discharge until their clinical and radiological features had stabilised. Patients who failed to attend were visited at home. A repeat chest radiographic and blood sample for serological testing were obtained at follow up. The main outcome measure was 30 day mortality.

\section{LABORATORY INVESTIGATIONS: CRITERIA FOR} MICROBIOLOGICAL DIAGNOSIS

Samples were held at $4^{\circ} \mathrm{C}$ and transported rapidly to the Nottingham Public Health Laboratory Service (PHLS) laboratory for standard and specialised investigations as previously described and summarised in table 1 . The criteria used to define infection in the 1982 BTS study were followed but updated for new techniques (table 1). ${ }^{3}$ The pathogens included in the term "atypical" pathogen are specified in table 3. Results for the BINAX-NOW pneumococcal antigen detection kit were read at 60 minutes instead of 15 minutes (as recommended by the manufacturers), based on the increased sensitivity of the 60 minute reading and no apparent difference in specificity $(100 \%)$ determined in a series of 50 cases of non-pneumococcal proven pneumonias (authors, unpublished data).

\section{STATISTICAL ANALYSIS}

Data were analysed using SPSS version 8.0 for Windows. $\chi^{2}$ or Fisher's exact tests were used to compare categorical variables. Multivariate analysis was performed by stepwise logistic regression. Results are expressed as odds ratios (ORs) with 95\% confidence intervals (CI) and $\mathrm{p}$ values, taking $\mathrm{p}<0.05$ as the level of statistical significance.

\section{Results}

Of 309 patients diagnosed with CAP on admission, eight were unwilling to participate 


\begin{tabular}{|c|c|}
\hline Characteristic & No $(\%)$ \\
\hline \multicolumn{2}{|l|}{ Age (years) } \\
\hline Mean (SD) & $65.4(19.6)$ \\
\hline Range & $18-97$ \\
\hline \multicolumn{2}{|l|}{ Age groups (years) } \\
\hline $18-44$ & $49(18)$ \\
\hline $45-64$ & $59(22)$ \\
\hline $65-74$ & $47(18)$ \\
\hline $75-84$ & $68(25)$ \\
\hline $85+$ & $44(16)$ \\
\hline Men & $135(51)$ \\
\hline Admitted from nursing home & $22(8)$ \\
\hline \multicolumn{2}{|l|}{ Smoking status } \\
\hline Current & $73(27)$ \\
\hline Ex-smoker (>6 months) & $100(37)$ \\
\hline Never & $80(30)$ \\
\hline Not known & $14(5)$ \\
\hline \multicolumn{2}{|l|}{ Alcohol consumed } \\
\hline None & $158(59)$ \\
\hline$<21$ units/week & 76 \\
\hline$\geqslant 21$ units/week & $15(6)$ \\
\hline Not known & 18 \\
\hline \multicolumn{2}{|l|}{ Vaccination status } \\
\hline Influenza vaccine (in last 12 months) & $76(28)$ \\
\hline Pneumococcal vaccine (in last 10 years) & $39(14.6)$ \\
\hline \multicolumn{2}{|l|}{ Comorbid illnesses } \\
\hline None & $83(31)$ \\
\hline Chronic lung disease & $82(31)$ \\
\hline Ischaemic heart disease & $33(12)$ \\
\hline Cardiac failure & $12(5)$ \\
\hline Cerebrovascular disease & $30(11)$ \\
\hline Diabetes mellitus & $22(8)$ \\
\hline Dementia & $22(8)$ \\
\hline Cancer & $15(6)$ \\
\hline Chronic liver disease & $2(0.7)$ \\
\hline Antibiotics prior to hospital admission & $104(39)$ \\
\hline Amoxycillin & 57 \\
\hline Macrolide & 22 \\
\hline
\end{tabular}

and 34 were subsequently found not to fulfil study entry criteria, leaving 267 patients in the study cohort, $112(41 \%)$ of whom were elderly (table 2). Of the 267 patients, 190 (71\%) were admitted over the winter (October to March), most in December and January $(n=88$ cases $(33 \%))$. Comorbid illnesses were more common in the elderly than in younger patients $(86 \%$ v $59 \%$; OR $4.1,95 \%$ CI 2.2 to 7.5 , $\mathrm{p}<0.001)$.

Table 3 No (\%) of pathogens detected in 267 adults studied according to age

\begin{tabular}{lllll}
\hline Pathogen & $\begin{array}{l}\text { Total }(\%) \\
(n=267)\end{array}$ & Died $(\%)$ & $\begin{array}{l}\text { Age }<75 \text { years } \\
(n=155)\end{array}$ & $\begin{array}{l}\text { Age } \geqslant 75 \text { years } \\
(n=112)\end{array}$ \\
\hline Bacterial pathogens & $144(54)$ & $19(13)$ & $88(57)$ & $56(50)$ \\
Streptococcus pneumoniae & $129(48)$ & $18(14)$ & $80(52)$ & $49(43)$ \\
Haemophilus influenzae & $20(7)$ & $1(5)$ & $11(7)$ & $9(8)$ \\
Moraxella catarrhalis & $5(2)$ & $0(0)$ & $1(0.6)$ & $4(4)$ \\
Staphylococcus aureus & $4(1.5)$ & $2(50)$ & $2(1)$ & $2(2)$ \\
GNEB & $4(1.4)$ & $1(25)$ & $3(1.9)$ & $1(0.9)$ \\
Anaerobes† & $3(1.1)$ & $0(0)$ & $2(1)$ & $1(0.9)$ \\
Atypical pathogens & $60(22)$ & $3(5)$ & $42(27)$ & $18(16)$ \\
Chlamydia pneumoniae & $35(13)$ & $2(6)$ & $20(13)$ & $15(13)$ \\
Mycoplasma pneumoniae & $9(3)$ & $0(0)$ & $8(5)$ & $1(0.9)$ \\
Legionella pneumophila & $9(3)$ & $1(11)$ & $8(5)$ & $1(0.9)$ \\
Chlamydia spp $\ddagger$ & $7(2)$ & $0(0)$ & $5(3)$ & $2(2)$ \\
Coxiella burnetti & $2(0.7)$ & $0(0)$ & $2(1)$ & $0(0)$ \\
Viral pathogens & $62(23)$ & $6(10)$ & $36(23)$ & $26(23)$ \\
Influenza virus A & $50(19)$ & $6(12)$ & $30(19)$ & $20(18)$ \\
Influenza virus B & $2(1)$ & $0(0)$ & $0(0)$ & $2(2)$ \\
Respiratory syncytial virus & $11(4)$ & $0(0)$ & $6(4)$ & $5(4)$ \\
Rhinovirus & $2(0.7)$ & $0(0)$ & $2(1.3)$ & $0(0)$ \\
Adenovirus & $1(0.4)$ & $0(0)$ & $1(0.6)$ & $0(0)$ \\
Pathogen not identified & $68(25)$ & $15(22)$ & $33(21)$ & $35(31)$
\end{tabular}

Pathogens were identified from bronchial washings in two patients ( $L$ pneumophilia, influenza A), post mortem lung tissue in one ( $S$ pneumoniae), and pleural fluid in one (Bacteroides spp). ${ }^{\star}$ Gram negative Enterobacteriaceae (details in text).

†Bacteroides spp isolated from pleural fluid in one patient, Fusobacterium necrophorum from blood of a patient with dental caries, and Gemella morbilloram from blood of another patient.

$\ddagger$ Excluding those found to be diagnostic in $C$ pneumoniae assays.
SPECIMEN COLLECTION

Specimens obtained included blood cultures prior to antibiotics in hospital from $225(84 \%)$ patients, acute serum from $250(94 \%)$ and follow up serum from $204(90 \%)$ survivors, urine from $214(80 \%)$ patients, and sputum within 24 hours of admission from 155 (58\%) patients, 128 of whom were tested for pneumococcal antigen.

AETIOLOGICAL AGENTS IDENTIFIED

Aetiological agents were found in 199 (75\%) patients: one pathogen in $124(46 \%)$, two in 53 $(20 \%)$, and three or more in $22(8 \%)$. Altogether, 144 (54\%) bacterial, 62 (23\%) viral, and $60(22 \%)$ atypical pathogens were detected (table 3).

\section{Bacterial pathogens}

The methods of diagnosing the 129 (48\%) pneumococcal cases are shown in detail in table 4. Only one penicillin resistant strain was isolated from blood culture of one patient. Pneumococcal infection was diagnosed in 90 of 163 patients $(55 \%)$ who had not received any antibiotics before admission compared with 39 of $104(37 \%)$ who had been treated with antibiotics (OR 2, 95\% CI 1.3 to 3.4, p=0.004). Staphylococcus aureus was isolated from the blood of two patients, both of whom had influenza $\mathrm{A}$ infection and required treatment in the intensive care unit within 24 hours of admission. Haemophilus influenzae and Moraxella catarrhalis were diagnosed by sputum culture in 11 (four ampicillin resistant) and two (one ampicillin resistant) cases, respectively, and by serological testing in 10 and four cases, respectively.

Of the four cases who fulfilled our criteria for aerobic Gram negative enterobacterial infection, both Klebsiella spp and Escherichia coli were isolated from blood culture in one patient. Pseudomonas aeruginosa was identified by Gram stain and culture from sputum in three patients with chronic lung disease and prior antibiotic use, two of whom recovered without receiving antipseudomonal therapy which strongly suggests that, in these cases, Pseudomonas was not an aetiological agent. Details of the three patients with anaerobic infection are given in table 3 .

\section{Atypical and viral pathogens}

Chlamydia pneumoniae was identified serologically in $35(13 \%)$ cases, more commonly in the winter (31 of 190 patients) than in the summer (four of $77 ; \mathrm{p}=0.015$ ).

Legionella pneumophila infection was diagnosed in nine patients (by urine antigen detection in seven and serological testing in eight). Three cases were associated with travel. There was no seasonal variation. Only two patients fulfilled the admission criteria for having severe pneumonia and both survived.

Atypical pathogens were found less often in elderly than in younger patients $(16 \% v 27 \%$; OR $0.5,95 \%$ CI 0.3 to $0.9, p=0.03$ ) both in the group as a whole and when divided into those with severe and non-severe infection (table 5). Their identification was not influenced by prior 
Table 4 Value of pneumococcal diagnostic tests for the 129 patients diagnosed as having pneumococcal infection

\begin{tabular}{llllll}
\hline & \multicolumn{5}{c}{ No (\%) positive } \\
\cline { 6 - 6 } \cline { 5 - 6 } Diagnostic test & $\begin{array}{l}\text { Sensitivity } \\
(\%)\end{array}$ & $\begin{array}{l}\text { Sole means } \\
\text { of diagnosis } \\
\text { (no of patients) }\end{array}$ & $\begin{array}{l}\text { Prior antibiotics } \\
(n=104)\end{array}$ & $\begin{array}{l}\text { No prior antibiotics } \\
(n=163)\end{array}$ & p value \\
\hline Blood culture & $9 / 114(8)$ & 3 & 0 & 9 & 0.01 \\
Urine antigen & $69+/ 114(61)$ & 31 & $17(16)$ & $52(32)$ & 0.005 \\
Serology & $78 / 123(63)$ & 36 & $26(25)$ & $53(33)$ & 0.19 \\
Sputum culture & $9 / 73(12)$ & 3 & 1 & 8 & 0.08 \\
Sputum CIE & $15 / 66(23)$ & 3 & 4 & 11 & 0.3
\end{tabular}

CIE = countercurrent electrophoresis.

${ }^{\star}$ Sensitivity $=$ proportion of patients with one or more positive pneumococcal test.

†49 were positive at 15 minutes. Of the remaining 20 , seven had pneumococcal infection diagnosed by other tests.

Table 5 Relationship between infection and atypical pathogen, age, and severity

\begin{tabular}{|c|c|c|c|}
\hline & \multicolumn{3}{|c|}{ Number with atypical pathogen detected } \\
\hline & Total $(n=60)$ & $\begin{array}{l}\text { Age }<75 \text { years } \\
(n=42)\end{array}$ & $\begin{array}{l}\text { Age } \geqslant 75 \text { years } \\
(n=18)\end{array}$ \\
\hline Total no of patients & 267 & 155 & 112 \\
\hline Total with atypical pathogen & $60(22 \%)$ & $42(27 \%)$ & $18(16 \%)$ \\
\hline $\begin{array}{l}\text { Proportion with severe infection who } \\
\text { had an atypical infection }\end{array}$ & $22 / 103(21 \%)$ & $11 / 41(27 \%)$ & $11 / 62(18 \%)$ \\
\hline $\begin{array}{l}\text { Proportion with non-severe infection } \\
\text { who had an atypical infection }\end{array}$ & $38 / 164(23 \%)$ & $31 / 114(27 \%)$ & $7 / 50(14 \%)$ \\
\hline Severe CAP (died) & $22(2)$ & $11(0)$ & $11(2)^{\star}$ \\
\hline Non-severe CAP (died) & $38(1)$ & $31(1) \dagger$ & $7(0)$ \\
\hline
\end{tabular}

antibiotic use. Only three of the 60 patients $(5 \%)$ with infection by an atypical pathogen died, two of whom had $C$ pneumoniae infection and one Legionella.

Of the 50 cases with influenza A virus infection, $38(76 \%)$ occurred in December and January. Respiratory syncytial virus (RSV) was the second most common viral pathogen identified. Of the $11 \mathrm{RSV}$ cases, at least one other pathogen was identified in nine (a bacterial pathogen in eight and influenza A virus in one).

\section{Mixed infections}

In infections in which Streptococcus pneumoniae was identified, co-pathogens were diagnosed in $60(47 \%)$ patients (influenza A virus in 25, $C$ pneumoniae in 20, H influenzae in nine, other atypical pathogens in four, and other viral pathogens in 11). Where $C$ pneumoniae infection was detected, a co-pathogen was diagnosed in $26(74 \%)$ cases (S pneumoniae in 20, influenza A virus in six, $H$ influenzae in four, other bacterial pathogens in four, and other viral pathogens in one). Overall, of 144 patients in whom infection with a bacterial pathogen was diagnosed, an atypical pathogen was also identified in $30(21 \%)$ cases and a viral pathogen in $41(28 \%)$ cases.

CLINICAL OUTCOME

Thirty day mortality was 15\% (40 patients); 35 patients died during hospital admission, seven within the first 24 hours, 12 within the first 2 days, and 22 within the first 4 days. The median length of stay in survivors was 7 days (1st and 3rd quartile values 4 and 11 days, respectively). Of 17 (6\%) patients admitted to the intensive care unit, five $(30 \%)$ died. The median time to admission to the intensive care unit was 1 day; $12(71 \%)$ were admitted within the first 24 hours of admission.

The mBTS severity prediction rule was $78 \%$ sensitive and $68 \%$ specific (negative predictive value (NPV) 95\%) at predicting death in comparison with the BTS original prediction rule ${ }^{3}$ which was $60 \%$ sensitive and $73 \%$ specific (NPV 91\%). For elderly patients aged 75 years or over the sensitivity $(77 \%)$ and NPV $(86 \%)$ of the mBTS rule remained high, although specificity was reduced to $53 \%$. Seven of 90 patients $(8 \%)$ with one of the four features in the mBTS rule died compared with 14 of 61 $(23 \%)$ with two features, 12 of 36 (33\%) with three features, five of six $(83 \%)$ with four features, and two of $74(2.7 \%)$ with no features present $\left(\chi^{2}\right.$ test for trend: odds ratio $2.8,95 \%$ CI 1.96 to $4.0, \mathrm{p}<0.001)$.

\section{Discussion}

This is the first UK study to employ a wide range of diagnostic tools to identify the aetiological agents in adult CAP, including $C$ pneumoniae, and to include patients aged 75 years and above. The high pathogen detection rate $(75 \%$ of cases) reassuringly found no substantial shift in the causes of CAP or antibiotic sensitivity in the UK over the last 20 years, with penicillin sensitive $S$ pneumoniae still the predominant causative agent in nearly half of cases. ${ }^{2-4}$ This is an important finding when reviewing management guidelines for this common condition, particularly as perceived changes in the pattern of CAP have led to changes in national antibiotic guidelines elsewhere. ${ }^{10}$

Pneumococcal infection was diagnosed less commonly in patients who had received antibiotics before admission, presumably due to decreased sensitivity of microbiological tests in this circumstance. ${ }^{3}$ None of the bacteraemic patients had received prior antibiotics. If prior antibiotic use is taken into account, then the true estimate of pneumococcal incidence is $55 \%$, similar to the 1982 BTS study.

This is the first UK report on $C$ pneumoniae infection in adult CAP and it was identified as the second most common pathogen. However, $C$ pneumoniae was frequently found in mixed infections, in over half of the cases with $S$ pneumoniae, as reported in other countries. $^{81112}$ Pathogens such as $C$ pneumoniae may play a role in promoting other bacterial infection through their effect on ciliated epithelial cells. ${ }^{13}$ The evidence regarding the importance of $C$ pneumoniae as a pathogen is conflicting. Some studies report that outcome is not affected when beta-lactam antibiotics alone are used for patients with evidence of $C$ pneumoniae infection. ${ }^{814}$ By contrast, studies from Finland have shown that mixed pneumococcal and $C$ pneumoniae infections cause more severe CAP than that associated with either pathogen alone. ${ }^{11}{ }^{14}$ Our study did not find this (data not shown). The number of patients fulfilling the criteria for severe infection were similar for these three groupings. The overall mortality in patients with pneumococcal infection was much higher than in those infected with $C$ pneumoniae (14\% v 6\%) 
and no patients with mixed pneumococcal and $C$ pneumoniae infection died. However, two elderly patients with $C$ pneumoniae infection alone died. Outbreaks associated with significant mortality have been reported in homes for the elderly in the USA. ${ }^{15}$

Our study supports the view that, unlike other atypical infections, $C$ pneumoniae infection affects adults of all ages, usually as a co-pathogen, and can be associated with severe infection and occasionally death. This provides support to the recommendations to include an antibiotic effective against atypical pathogens for patients of all ages with severe CAP. ${ }^{5}$

The frequency of $L$ pneumophilia infection was lower than the $15 \%$ we reported 17 years ago, a trend seen in other countries. ${ }^{216}$ Although yearly variation may partly explain these findings, ${ }^{17}$ increased use of macrolides in the community may also be relevant. ${ }^{16}$ Most of our cases had non-severe CAP, contrary to the view that Legionella infection is usually severe. ${ }^{18}$ All our cases received an early macrolide as part of their hospital treatment, possibly influencing our low mortality. Delayed treatment for Legionella infection relates to increased mortality. ${ }^{19}$ Furthermore, the report of a positive Legionella urine antigen test within 3 days of admission positively influenced early management in seven of nine patients, emphasising the likely value of urine antigen detection as a rapid diagnostic tool for patients admitted to hospital with CAP.

Infection with $M$ pneumoniae was uncommon which is probably explained by the four yearly cycle of mycoplasma epidemics in Europe; our study coincided with the tail end of a national epidemic. ${ }^{3}$ Our mycoplasmal pneumonia rate of $3 \%$ is similar to the $2 \%$ reported in 1982 , contrasting with the $14 \%$ and $18 \%$ rates reported in UK studies during epidemic years. ${ }^{24}$ Ready access to current epidemiological trends, as is available on the PHLS website (www.phls.co.uk), could be useful to clinicians for planning empirical antibiotic management.

Most of the cases of influenza were complicated by bacterial co-infections, emphasising the importance of influenza prevention. Only 68 of 175 eligible patients (39\%) had received the influenza vaccine in the preceding 12 months, higher than the estimated $23 \%$ vaccine uptake among high risk patients in England and Wales in 1996/7 but still an area that can be improved. ${ }^{20}$ Similarly, pneumococcal vaccination in the last 10 years was reported in only 29 $(25 \%)$ of 114 eligible patients.

IMPLICATIONS FOR THE MANAGEMENT OF CAP How does this study contribute to the development of an up to date management strategy for patients hospitalised with CAP?

Nearly all hospitals in the UK now operate an integrated emergency admission policy for adults of all ages, many of whom are elderly. Our patient cohort is typical of the pattern of CAP in the UK with half aged 65 years and above and about $40 \%$ over 75 years. ${ }^{121}$ We have shown that penicillin sensitive $S$ pneumoniae remains the most important pathogen in adults of all ages admitted with CAP and this should be covered effectively by the chosen empirical antibiotic. Ampicillin resistant bacteria are uncommon and concerns regarding Gram negative enterobacterial infections in the elderly seem unfounded.

Our study confirmed that pneumococcal, Haemophilus, and staphylococcal infections are the usual bacterial pathogens implicated in fatal CAP and such pathogens should always be covered by initial antibiotic therapy for severe pneumonia. We also recommend that empirical cover for atypical pathogens should be offered to all patients with severe CAP as $21 \%$ of our patients with atypical infection had features of severe pneumonia and three died. This is also important as several previous studies have found Legionella infection to be the second most common cause of CAP requiring intensive care. ${ }^{318}$ The high proportion of patients who died or needed admission to the intensive care unit within the first few days of hospital admission emphasises the need for early identification of patients with severe pneumonia. The modified BTS rule performs better than the BTS rule in this regard, with sensitivity and NPV values being high, even in the elderly population. We found that patients could be stratified into increasing mortality risk groups using the four individual "core" features of the mBTS rule (CURB: Confusion, Urea, Respiratory rate, Blood pressure)-a strategy which may be more useful in management than just two categories of severe and non-severe. The "post-take" ward round is recommended as a good time to review patients and to decide on step up or step down of treatment options.

For non-severe CAP our study supports the use of empirical antibiotic cover for atypical pathogens for younger patients admitted to hospital but not for elderly patients. Atypical pathogens were twice as common in younger patients and led to no deaths in elderly patients presenting with features of non-severe pneumonia. Avoidance of early routine combination antibiotics, including a macrolide, in this latter patient group would probably be of net advantage in view of the complications of multiple antibiotic use in the elderly.

Overall, this study supports the current UK recommendations for covering the range of pathogens found in the management of CAP, stratified according to disease severity. Rapid urine antigen testing looks promising as an early way of detecting some pathogens including $S$ pneumoniae and $L$ pneumophila. More experience is needed before recommending these tests as a reliable way of directing more accurately the initial antibiotic choice for CAP.

We would like to thank Hoechst Marion Roussel for supporting this study through a research grant and Binax for providing the Streptococcus pneumoniae Binax-NOW antigen detection kits free. We are grateful to all who contributed in different ways to free. We are grateful to all who contributed in different ways to
this study: Robert Cave, Joanne Palfryman and the team of this study: Robert Cave, Joanne Palfryman and the team of
technical and medical staff at Nottingham Public Health Labotechnical and medical staff at Nottingham Public Health Laboratory for their dedication to the study, Anne Jaakkola in
Finland who coordinated the microbiology specimens, and phyFinland who coordinated the microbiology specimens, and phy-
sicians at Nottingham City Hospital for allowing us to study sicians at Nottin
their patients. 
Conflicts of interest: TB has received research funding from Eisai Ltd and support for attending conferences from Wyeth. WSL has teceive Roussel (this study) and Bayer and support for attending conferences from Bayer. JTM has received consultancy fees from Pfizer, Abbott, Hoechst Marion Roussel, Trinity, Glaxo Wellcome, research funding from Hoechst Marion Roussel (this study), Rhone Poulenc Rorer and Bayer, lecture fees from AstraZeneca, Hoechst Marion Roussel and Pfizer and support for attending conferences from Astra, Pfizer, Allen and Hanbury and $3 \mathrm{M}$.

1 Guest JF, Morris A. Community acquired pneumonia: the annual cost to the National Health Service in the UK. Eur Respir 7 1997;10:1530-4.

2 Macfarlane JT, Ward MJ, Finch RG, et al. Hospital study of adult community acquired pneumonia. Lancet 1982; $255-8$.

3 Anonymous. Community-acquired pneumonia in adults in British hospitals in 1982-1983: a survey of aetiology, mortality, prognostic factors and outcome. The British Thoracic Society and the Public Health Laboratory Service. $O$ f Med 1987;62:195-220.

4 White RJ, Blainey AD, Harrison $\mathrm{KJ}$, et al. Causes of pneumonia presenting to a district general hospital. Thorax pneumonia prese

5 British Thoracic Society. Guidelines for the management of community-acquired pneumonia in adults admitted to hospital. Br f Hosp Med 1993;49:346-50.

6 Marrie TJ, Blanchard W. A comparison of nursing home-acquired pneumonia patients with patients with community-acquired pneumonia and nursing home patients without pneumonia. 7 Am Geriatr Soc 1997;45:50-5.

7 Neill AM, Martin IR, Weir R, et al. Community acquired pneumonia: aetiology and usefulness of severity criteria on admission. Thorax 1996;51:1010-6.

8 Lieberman D, Schlaeffer F, Boldur I, et al. Multiple pathogens in adult patients admitted with community acquired pneumonia: a one year prospective study of 346 consecutive patients. Thorax 1996;51:179-84.

9 Steinhoff D, Lode H, Ruckdeschel G, et al. Chlamydia pneumoniae as a cause of community-acquired pneumonia in moniae as a cause of community-acquired pneumonia in hospitalized patients in Berlin. Clin Infect Dis 1996;22:958-

10 Bartlett JG, Breiman RF, Mandell LA, et al. Communityacquired pneumonia in adults: guidelines for management. The Infectious Diseases Society of America. Clin Infect Dis 1998;26:811-38.

11 Kauppinen MT, Herva E, Kujala P, et al. The etiology of community-acquired pneumonia among hospitalized patients during a Chlamydia pneumoniae epidemic in Finland f Infect Dis 1995;172:1330-5.

12 Marrie TJ, Grayston JT, Wang SP, et al. Pneumonia associated with the TWAR strain of Chlamydia. Ann Intern Med 1987;106:507-11.
13 Shemer-Avni Y, Lieberman D. Chlamydia pneumoniaeinduced ciliostasis in ciliated bronchial epithelial cells. $\mathcal{F}$ Infect Dis 1995;171:1274-8.

14 Kauppinen MT, Saikku P, Kujala P, et al. Clinical picture of community-acquired Chlamydia pneumoniae pneumonia requiring hospital treatment: a comparison between chlamydial and pneumococcal pneumonia. Thorax 1996; 51:185-9.

15 Troy CJ, Peeling RW, Ellis AG, et al. Chlamydia pneumoniae as a new source of infectious outbreaks in nursing homes. $\mathcal{F} A M A$ 1997;277:1214-8 (published erratum appears in FAMA 1997;278:118).

16 Ruiz M, Ewig S, Torres A, et al. Severe community-acquired pneumonia. Risk factors and follow-up epidemiology. Am $\mathcal{f}$ Respir Crit Care Med 1999;160:923-9.

17 Woodhead MA, Macfarlane JT, Macrae AD, et al. The rise and fall of Legionnaires' disease in Nottingham. F Infect 1986;13:293-6.

18 Woodhead MA, Macfarlane JT, Rodgers FG, et al. Aetiology and outcome of severe community-acquired pneumonia. $\mathcal{F}$ Infect 1985;10:204-10.

19 Heath $\mathrm{CH}$, Grove DI, Looke DF. Delay in appropriate therapy of Legionella pneumonia associated with increased mortality. Eur 7 Clin Microbiol Infect Dis 1996;15:286-90.

20 Irish C, Alli M, Gilham C, et al. Influenza vaccine uptake and distribution in England and Wales, July 1989 to June 1997. Health Trends 1998;30:51-5.

21 Lim WS, Lewis S, Macfarlane JT. Severity prediction rules in community acquired pneumonia: a validation study. Thorax 2000;55:219-23.

22 Jalonen E, Paton JC, Koskela M, et al. Measurement of antibody responses to pneumolysin: a promising method for the presumptive aetiological diagnosis of pneumococcal pneumonia. F Infect 1989;19:127-34.

23 Leinonen M, Syrjala H, Jalonen E, et al. Demonstration of pneumolysin antibodies in circulating immune complexes: a new diagnostic method for pneumococcal pneumonia. Serodiagn Immunother Infect Dis 1990;4:451-8.

24 Burman LA, Leinonen M, Trollfors B. Use of serology to diagnose pneumonia caused by nonencapsulated Haemophilus influenzae and Moraxella catarrhalis. F Infect Dis 1994; 170:220-2.

25 Dominguez J, Gali N, Matas L, et al. Evaluation of a rapid immunochromatographic assay for the detection of $\mathrm{Le}$ gionella antigen in urine samples. Eur $\mathcal{F}$ Clin Microbiol Infect Dis 1999;18:896-8.

26 Helbig JH, Ullman SA, Luck PC, et al. Detection of Legionella pneumophila antigen in urine samples using the Binax Now immunochromatographic assay and comparison with both Binax Legionella urinary enzyme immunoassay (EIA) and Biotest Legionella urine antigen EIA. 7 Med Microbiol 2001 (in press).

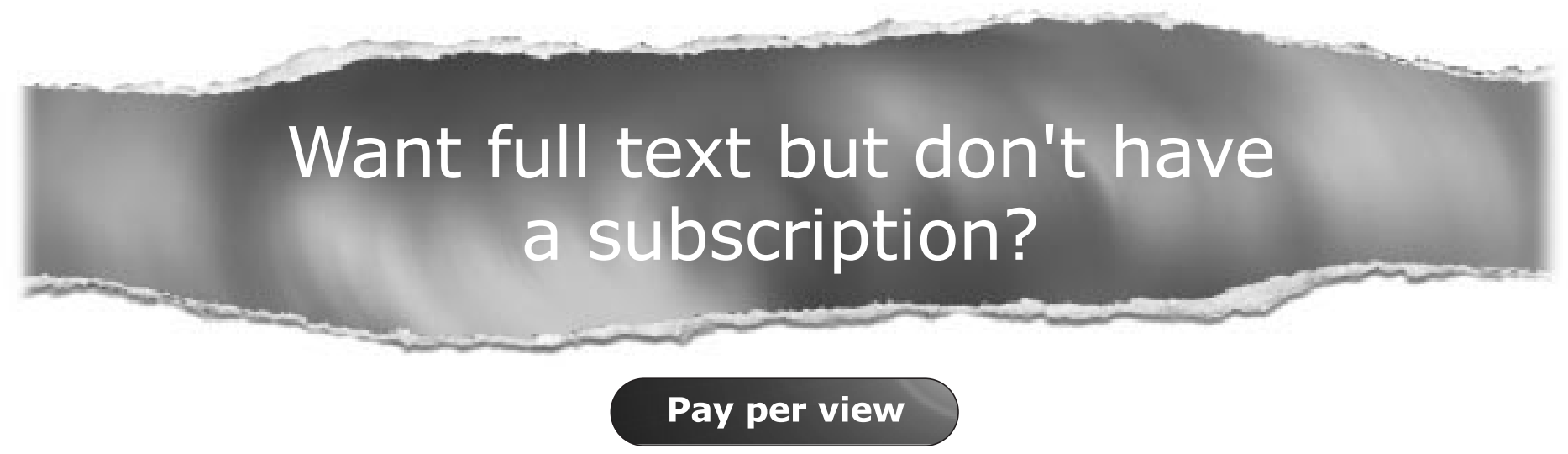

For just $\$ 8$ you can purchase the full text of individual articles using our secure online ordering service. You will have access to the full text of the relevant article for 48 hours during which time you may download and print the pdf file for personal use.

www.thoraxjnl.com 